\title{
Revisitando Tomás de Aquino - quatro aspectos de Ética e Educação
}

\author{
Thomas Aquinas on Ethics and Education - \\ four aspects
}

\section{Tomás de Aquino: Ética e Educación - quatro aspectos}

Jean Lauand*

\begin{abstract}
RESUMO
Tomás de Aquino (1224/5-1274) é, talvez, o mais importante pensador medieval. Sua filosofia - indissociável da teologia, em sua época - tem importantes projeções pedagógicas, também para o educador de hoje, para além do interesse meramente histórico. Neste estudo, destacaremos quatro aspectos da ética tomista, de especial atualidade para a educação: a sua concepção de ética; a valorização do corpo e da matéria; a virtude cardeal da prudentia; e o pecado capital da acídia.
\end{abstract}

Palavras-chave: Tomás de Aquino; ética; educação; prudência; acídia.

\begin{abstract}
Thomas Aquinas $(1224 / 5$ - 1274) is perhaps the most important medieval thinker. His philosophical-theological thought has pedagogical implications, important even for our time. This study is about four aspects of Aquinas's ethics and moral education: ethics and its foundations, his view of body, the cardinal virtue of prudence and the capital sin of sloth. Keywords: Thomas Aquinas; ethics; education; prudence; sloth.

\section{RESUMEN}

Tomás de Aquino (1224/5 - 1274) es talvez el mas importante pensador medieval. Su filosofía - indisociable de la teología en su época - trae consigo importantes proyecciones pedagógicas, también para el educador de hoy. En este estudo se contemplan cuatro aspectos de la ética tomasiana, de especial actualidad para la educación: su misma concepción de ética; su visión del cuerpo; la virtude cardenal de la prudentia; y el pecado capital de la acedia. Palabras clave: Tomás de Aquino; ética; educación; prudência; acedia.
\end{abstract}

* Professor Titular Sênior da Faculdade de Educação da Universidade de São Paulo (USP) e dos Programas de Pós-Graduação em Educação e Ciências da Religião da Universidade Metodista de São Paulo (UMESP). Contato: jeanlaua@usp.br 


\section{Introdução}

Tomás de Aquino (1224/5-1274) talvez seja o mais importante pensador medieval. Sua filosofia - indissociável da teologia, em sua época - tem importantes projeções pedagógicas, também para o educador de hoje, para além do interesse meramente histórico. Neste estudo, destacaremos quatro aspectos da ética tomista, de especial atualidade para o educador: a sua concepção de ética; a valorização do corpo e da matéria; a virtude cardeal da prudentia; e o pecado capital da acídia.

A vida de Tomás de Aquino está centrada no séc. XIII. Desde o século anterior - um século de renascimento cultural, após um longo período de aridez intelectual - já se estabeleciam as condições que possibilitariam as profundas inovações trazidas pelo pensamento do Aquinate.

De fato, com a queda do Império Romano no Ocidente (consumada em 476) e consequente instalação de reinos bárbaros no espaço geográfico da extinta Roma, a primeira Idade Média encontrava-se em condições precárias de cultura e educação. O esplendor da cultura clássica foi substituído pela "idade das trevas": tribos bárbaras, não só analfabetas, mas (até há pouco) ágrafas, são a nova realidade dominante na Europa.

Do ponto de vista cultural e pedagógico, alguns autores, como Josef Pieper, preferem estabelecer o ano 529 como marco inicial da Idade Média. Nesse ano, ocorrem dois fatos emblemáticos: o imperador Justiniano (o império romano no Oriente permanecerá até 1453) fecha a Academia de Atenas: já não haverá lugar para a cultura pagã. E São Bento funda o mosteiro de Monte Cassino: não por acaso, os primeiros séculos medievais são, na História da Educação, chamados de "Idade Beneditina".

Os mosteiros beneditinos serão, em meio à desolação cultural da primeira Idade Média, o refúgio onde se alojará e conservará o pouco conhecimento que restou do fim da Antiguidade. Graças a educadores como Boécio e Cassiodoro.

Boécio, o "último romano", um dos mais importantes nomes da história da educação, foi encarregado pelo rei Teodorico de organizar a cultura no reino ostrogodo. Conhecedor profundo da ciência e da filosofia gregas, Boécio empreende um projeto pedagógico realista: uma cultura de resumos. Ele sabe que o esplendor da cultura grega e romana desapareceu e que a nova realidade são os ostrogodos, incapazes de ascenderem às alturas do mundo clássico. E empreende, na corte do rei, uma pedagogia de traduções e conteúdos mínimos: a imponente geometria de Euclides, a aritmética, a astronomia são reduzidas a livrinhos elementares e sumaríssimos. Embora suas ambições para a filosofia fossem muito maiores, sua trágica morte (em 525, 
quatro anos antes do aparecimento da ordem beneditina) deixou o Ocidente sem traduções de Platão e com muito pouco de Aristóteles.

Boécio, uma inteligência superior e conhecedor profundo da cultura clássica, tinha talento para muito mais do que para resumos e traduções, mas, como grande educador, optou pela tarefa exigida por sua época: o trabalho obscuro e pouco original de elaboração de sementes secas, que pudessem, um dia, em futuro longínquo, germinar, florescer e frutificar.

Cassiodoro, também um culto romano, colega de Boécio na corte de Teodorico, percebeu que não havia condições de cultivo do saber na tumultuada corte do reino bárbaro e, em 555, fundou o mosteiro de Vivarium, marco importante na história da educação. Curiosamente, os bárbaros, em geral, respeitavam o espaço sagrado do mosteiro e Vivarium tornara-se um paradigma para a Europa: a partir de então, o mosteiro será não só um lugar de oração, mas também de cultura: de estudo e cópia de livros e de ensino elementar.

Nos séculos XII e XIII, ocorrem mudanças significativas: intensifica-se a urbanização e muda também o centro de gravidade da educação: das escolas monásticas para as escolas catedrais e as nascentes universidades. Surgem as ordens mendicantes, os dominicanos (à qual Tomás se filiará) e os franciscanos; renascem as ciências e redescobre-se Aristóteles (inicialmente por meio de traduções do árabe na Espanha reconquistada) etc.

Se, na primeira Idade Média, o pensamento estivera praticamente limitado aos livros de Sentenças, compilação de pensamentos dos santos padres, e à preservação com pouco desenvolvimento daquela "cultura de resumos", legada por Boécio, Cassiodoro ou Isidoro de Sevilha; agora, com o renascimento cultural do séc. XII, já podem ser elaboradas as Sumas, grandiosas sínteses pessoais, como a Suma Teológica de Tomás, que inclui a "novidade" do pensamento aristotélico: com sua valorização do corpo e suas agudas análises éticas.

Nesse ambiente de efervescência intelectual é que se desenvolve, contra a corrente, o pensamento de Tomás, um dos primeiros membros da ordem dominicana e um dos primeiros grandes professores da Universidade de Paris, ambas fundadas em 1215.

\section{A ética no pensamento de Tomás}

Antes de analisarmos a importância do corpo, a prudência e a acídia, é necessário lembrar - e enfaticamente - que a ética de Tomás é uma ética do ser, da autorrealização do homem.

O homem de hoje tem dificuldade para compreender essa moral porque, desligado do ser - e essa "desatualidade" de Tomás é também sua profunda 
atualidade -, ao pensar em moral, costuma imaginar alguma coisa ligada a regras e proibições, imposições mais ou menos incômodas e arbitrárias procedentes dos pais, professores, ministros religiosos, enfim, limitações à liberdade feitas pela sociedade.

Totalmente outra é a concepção de Tomás. Ele nem sequer poderia conceber a moral como algo imposto, nem como "assunto reservado a religiosos" e, menos ainda, como algo constrangedor ou repressivo da liberdade humana! O que ele diz, sim, é que a moral é o ser do homem ${ }^{1}$, doutrina sobre o que o homem é e está chamado a ser.

Sim, porque, para Tomás, a moral é entendida como um processo de autorrealização do homem² ${ }^{2}$ um processo levado a cabo livre e responsavelmente e que incide sobre o nível mais fundamental, o do ser-homem: "Quando, porém, se trata da moral, a ação humana é vista como afetando, não um aspecto particular, mas a totalidade do ser do homem...; ela diz respeito ao que se é enquanto homem" (Summa Theol. I-II, 21, 2 ad 2). ${ }^{3}$

Note-se que estamos caracterizando a ética, falando de realização (no singular), e não de realizações (plural) nos diversos aspectos setoriais da vida: financeiro, saúde, status, etc... Pois a ética diz respeito precisamente à realização; realização não deste ou daquele aspecto parcial, mas a que afeta a totalidade, o que se é enquanto homem.

Tomás tem da ética uma visão profunda e orgânica, que deriva da própria natureza do ser humano. Nesse sentido, é interessante observar que o Aquinate afirma diversas vezes que a Criação é obra de toda a Santíssima Trindade e que constitui uma união de ser, verdade e bem que espelha a Unidade das três Pessoas divinas: Pai, Filho e Espírito Santo. "Deus Pai opera a Criação pelo seu Verbo, que é o Filho, e pelo seu Amor, que é o Espírito Santo" (Summa Theol. I, 45, 6). Assim, o ato de criar, de "conferir o ser", está unido ao Pensamento divino, ao Logos, ao Verbo que, juntamente com o ser, dá "verdade" e inteligibilidade à criatura: ao criá-la, dota-a daquela natureza, daquele modo de ser, que pode ser objeto de análise racional.

Todo ente tem, portanto, uma essência (não rígida e acabada, mas aberta como veremos ao examinar a Prudência), uma ratio, uma natureza, um modo de ser pensado, planejado por Deus; está organizado ou estruturado segundo um "projeto" divino. O homem (e cada coisa criada) é o que é, possui uma

\footnotetext{
Confira, por exemplo, o Prólogo da parte II da Suma Teológica.

É o que significa, por exemplo, a caracterização, tantas vezes por ele repetida, da virtude como ultimum potentiae.

3 Todas as citações do Aquinate procedem do texto latino da edição eletrônica das obras completas de Tomás de: BUSA, Roberto. Thomae Aquinatis Opera Omnia cum hypertextibus in CD-ROM. Milano: Editoria Elettronica Editel, 1992.
} 
natureza humana, precisamente por ter sido criativamente criado pelo Verbo. Daí que haja uma verdade e um bem objetivos para o homem, porque seu ser não é caótico ou aleatório, mas procede de um design divino.

É, pois, ao homem que se dirige a ética de Tomás; ao homem total, espírito em intrínseca união com a matéria; ao homem, ser-em-potência, que ainda não atingiu a estatura a que está chamado e para quem a ética se expressa na famosa sentença do poeta grego Píndaro: “Torna-te o que és!”.

Nesta perspectiva, toda norma moral deve ser entendida como um enunciado a respeito do ser do homem; e toda transgressão moral, o pecado, traz consigo uma agressão ao que o homem é. Os imperativos dos mandamentos (“Farás x...", “Não farás y...”) são, no fundo, enunciados sobre a natureza humana: "O homem é um ser tal que sua felicidade, sua realização, requer x e é incompatível com y".

Em resumo, é precisamente à ética - e no sentido que lhe dá Tomás que se refere a famosa sentença "To be or not to be: that is the question".

\section{Valorização do corpo e da matéria}

Assim, o pensamento de Tomás é o que há de mais oposto ao maniqueísmo, aquela doutrina herética que afirma a existência de dois princípios substanciais: o do bem (correspondente ao espírito) e o do mal (à matéria): Tomás, ao afirmar a criação, afirma a bondade de tudo o que é. É bom o espírito humano e são bons também o vinho, a comida, o prazer sexual etc.

O mal, o pecado, nesse enquadramento, é simplesmente uma desordem, uma distorção, um desequilíbrio, um mau uso, um voltar-se indevido para algo que em si é bom, criado por Deus: o prazer da bebida, por exemplo, em si, é bom e previsto por Deus para fins bons, mas, evidentemente, pode ser usado de modo autodestruidor.

Assim, no centro da filosofia da educação de Tomás, encontra-se a tese fundamental de sua antropologia: anima forma corporis, a profunda unidade, no homem, entre espírito e matéria: a alma é forma substancial, em intrínseca união com a matéria.

Essa tese, originariamente aristotélica, não era, como se sabe, bem vista nos meios teológicos da época: era considerada perigosa para um cristianismo que não valorizava a matéria e o corpo; a doutrina teológica dominante pretendia uma concepção demasiadamente espiritualista do homem: o homem possuiria três almas e a alma verdadeiramente importante seria a espiritual (e não as duas corpóreas: sensitiva e vegetativa) e a condição carnal era considerada, antes, um estorvo para a elevação do espírito.

Contra essas antropologias "angelistas", Tomás - corajosa e decididamente - afirma o homem total, com a intrínseca união espírito-matéria, pois a alma 
é forma: co-princípio ordenado para a intrinseca união com a matéria. Quando Tomás diz: "É evidente que o homem não é só a alma, mas um composto de alma e de corpo" (Summa Theol. I, 75, 4) esse "é evidente", na verdade, refere-se à verdade das coisas e não às opiniões teológicas de seu tempo...

Esse "materialismo" de Tomás está presente in-formando todo seu pensamento, por exemplo: quando discute o jejum excessivo nas questões de Quodlibet, dirá que o jejum é, sem dúvida, pecado (absque dubio peccat) quando debilita a natureza a ponto de impedir as ações devidas: que o pregador pregue; que o professor ensine; que o cantor cante; que o marido tenha potência sexual para atender sua esposa! Aquele que assim se abstém de comer ou de dormir oferece a Deus um holocausto que é fruto de um roubo (Quodl. 5, q. 9, a. 2, c).

Tomás aceita tão completamente o corpo como integrante essencial da realidade do ser humano, que esta união se projeta até na operação espiritual que é o conhecimento intelectual: "A alma necessita do corpo para conseguir o seu fim, na medida em que é pelo corpo que adquire a perfeição no conhecimento e na virtude" (Contra Gentiles 3, 144.).

E, contra aquela tradição teológica que afirmava a iluminação imediata da inteligência humana por Deus (para o Aquinate, Deus nos deu sua luz, dando-nos o intelecto), Tomás afirma que só podemos chegar às ideias mais abstratas e às considerações mais espirituais a partir da realidade sensível, material, concreta: "O intelecto humano, que está acoplado ao corpo, tem por objeto próprio a natureza das coisas existentes corporalmente na matéria. $\mathrm{E}$, mediante a natureza das coisas visíveis, ascende a algum conhecimento das invisíveis" (Summa Theol. I, 84, 7).

Nesta afirmação, resume-se a própria estrutura ontológica do homem. E, insistamos, mesmo as realidades mais espirituais só são alcançadas, por nós, através do sensível: "Ora - prossegue Tomás -, tudo o que nesta vida conhecemos, é conhecido por comparação com as coisas sensíveis naturais".

Esse voltar-se para o concreto, para o sensível, marca profundamente não só a pedagogia, mas é mesmo uma clave de interpretação para todo o pensamento de Tomás de Aquino.

\section{A primazia da virtude cardeal da prudentia}

Com uma antropologia centrada na ideia de Criação (da Razão: Logos divino), decorre o extraordinário papel que Tomás confere à virtude da Prudência. É difícil subestimar a importância da virtude da Prudência, a principal das quatro virtudes cardeais (prudência, justiça, fortaleza e temperança), no pensamento de Tomás: não é que ela seja a primeira inter pares, mas é 
principal em uma ordem superior, é a mãe das virtudes, genitrix virtutum (In III Sent., d 33, q 2, a 5, c) e a guia das virtudes, auriga virtutum (In IV Sent., d 17, q 2, a 2, dco).

Por mais destacada, porém, que seja a importância histórica do Tratado da Prudência de Tomás, seu interesse transcende o âmbito da história das ideias e instala-se - superadas as naturais barreiras de linguagem dos séculos que nos separam do Aquinate - no diálogo direto com o educador de nosso tempo, como rica contribuição para alguns de nossos mais urgentes problemas existenciais.

Para bem avaliar o significado e o alcance do Tratado da Prudência, é necessário, antes de qualquer coisa, atentar para o fato de que "prudência" é uma daquelas tantas palavras fundamentais que sofreram desastrosas transformações semânticas com o passar do tempo: aquela palavra que, originalmente, designava uma qualidade positiva, esvazia-se de seu sentido inicial ou passa até a designar uma qualidade negativa.

"Prudência" já não designa, hoje, a grande virtude, mas sim a conhecida cautela (um tanto oportunista, ambígua e egoísta) ao tomar (ou ao não tomar...) decisões. Se hoje a palavra prudência tornou-se aquela egoísta cautela da indecisão "em cima do muro", em Tomás, ao contrário, ela expressa exatamente o oposto da indecisão: é a arte de decidir-se corretamente, isto é, com base não em interesses oportunistas, não em sentimentos piegas, não em impulsos, não em temores, não em preconceitos etc., mas, unicamente, com base na realidade: em virtude do límpido conhecimento do ser. É este conhecimento do ser (sem dúvida imperfeito e assintótico) que é significado pela palavra ratio na definição de prudentia: recta ratio agibilium, "reta razão aplicada ao agir", como repete, uma e outra vez, Tomás.

Prudência é encarar a realidade e, com base nessa visão, tomar a decisão certa. Por isso, como repete Tomás, não há nenhuma virtude moral sem a prudência, e mais: "sem a prudência, as demais virtudes, quanto maiores fossem, mais dano causariam" (In III Sent. d 33, q 2, a 5, sc 3). Com as alterações semânticas, porém, tornou-se intraduzível, para o homem de nosso tempo, uma sentença de Tomás como: "a prudentia é necessariamente corajosa e justa". 4

Sem esse referencial, tomamos nossas decisões fundamentados em quê? Quando não há a simplicitas, a simplicidade da prudência que busca a realidade como único ponto decisivo na decisão, ela acaba sendo tomada, como dizíamos, com base em diversos outros fatores: por preconceitos, por interesses interesseiros, por impulso egoísta, pela opinião coletiva, pelo "politicamente correto", por inveja ou por qualquer outro vício...

Nec prudentia vera est quae iusta et fortis non est. (Summa Theol. I-II, 65, 1). 
Para o educador, é interessante notar que o "Tratado da Prudência" de Tomás é o reconhecimento de que a direção da vida é competência de cada pessoa, e o caráter dramático da prudentia se manifesta claramente quando Tomás mostra que não há "receitas" de bem agir, não há critérios comportamentais operacionalizáveis, porque - e esta é outra constante no Aquinate - a prudentia versa sobre ações contingentes, situadas no "aqui e agora".

E é que a prudentia é virtude da inteligência, mas da inteligência do concreto: a prudentia não é a inteligência que versa sobre teoremas ou princípios abstratos e genéricos, não! Ela olha para o "tabuleiro de xadrez" da situação "aqui e agora", sobre a qual se dão nossas decisões concretas, e sabe discernir o "lance" certo, moralmente bom. E o critério para esse discernimento do bem é: a realidade! Saber discernir, no emaranhado de mil possibilidades que esta situação me apresenta (que devo dizer a este aluno?, compro ou não compro?, caso-me ou não?, devo responder a este email? etc.), os bons meios concretos que me podem levar a um bom resultado, à plenitude da minha vida, minha realização enquanto homem. E, para isto, é necessário ver a realidade concretamente. De nada adiantam bons princípios abstratos, sem a prudentia que os aplica - como diz Tomás - ao "outro polo": o da realidade (o que significa "amar o próximo" nesta situação concreta?).

A condição humana é tal que - muitas vezes - não dispomos de regras operacionais concretas: sim, há um certo e um errado objetivos, um "to be or not to be" pendente de nossas decisões, mas não há regra operacional. Tal como para o bom lance no xadrez, há até critérios gerais objetivos... mas não operacionais!

Nessa mesma linha, está a agudíssima página de GUIMARÃES ROSA (1967, p. 366) - todo um tratado de filosofia da educação moral nas palavras do jagunço Riobaldo:

Sempre sei, realmente. Só o que eu quis, todo o tempo, o que eu pelejei para achar, era uma só coisa - a inteira - cujo significado e vislumbrado dela eu vejo que sempre tive. A que era: que existe uma receita, a norma dum caminho certo, estreito, de cada uma pessoa viver - e essa pauta cada um tem - mas a gente mesmo, no comum, não sabe encontrar; como é que sozinho, por si, alguém ia poder encontrar e saber? Mas, esse norteado, tem. Tem que ter. Se não, a vida de todos ficava sendo sempre o confuso dessa doideira que é. E que: para cada dia, e cada hora, só uma ação possível da gente é que consegue ser a certa. Aquilo está no encoberto: mas, fora dessa consequência, tudo o que eu fizer, o que o senhor fizer, o que o beltrano fizer, o que todo-o-mundo fizer, ou deixar de fazer, fica sendo falso, e é o errado. Ah, porque aquela outra é a lei, escondida e vivível, mas não achável, do verdadeiro viver: que para cada pessoa, sua continuação, já foi projetada, como o que se põe, em teatro, para cada representador - sua parte, que antes já foi inventada, num papel... 
Trata-se, assim, de uma "inteligência" moral, a insubornável fidelidade ao real, que aprende da experiência e, portanto, requer a memória como virtude associada: a limpidez da memória fiel à realidade, que não distorce a verdade dos fatos passados.

Se ver a realidade é uma parte da prudência; a outra parte, ainda mais decisiva (literalmente), é transformar a realidade vista em decisão de ação, em comando: de nada adianta saber o que é bom, se não há a decisão de realizar este bem.

O nosso tempo, que se esqueceu até do verdadeiro significado da clássica prudentia, atenta contra ela de diversos modos: em sua dimensão cognoscitiva (a capacidade de ver o real, por exemplo, aumentando o ruído - exterior e interior - que nos impede de "ouvir" a realidade - o nosso tempo praticamente suprimiu o silêncio, tão necessário para a vida do espírito) e em sua dimensão prescritiva, no ato de comandar: o medo de enfrentar o peso da decisão, que tende a paralisar os imprudentes (pois, insistamos, a prudência toma corajosamente a decisão boa!).

A grande tentação da imprudência (sempre no sentido clássico) é a de transferir para outras instâncias o peso da decisão que, para ser boa, depende só da visão da realidade. Há diversas formas dessa abdicação: do abuso de reuniões desnecessárias à delegação das decisões a terapeutas, comissões, analistas, ministros religiosos e gurus, passando por toda sorte de consultas esotéricas.

Uma das mais perigosas formas de renúncia a enfrentar a realidade (ou seja, a renúncia à prudentia) é trocar essa fina sensibilidade de discernir o que, naquela situação concreta, seria a decisão boa, por critérios operacionais rígidos, como num "Manual de escoteiro moral" ou, no campo do direito, num estreito legalismo à margem da justiça. É também o caso do radicalismo adotado por certas propostas religiosas. Tal como o "Ministério do Vício e da Virtude", do antigo regime Taliban, algumas comunidades cristãs - em vez de afirmar o direito (e o dever) do fiel de discernir o que é bom em cada situação pessoal concreta de sua vida - simplificam grosseiramente: em caso de dúvida, é pecado e pronto!

A prudentia é ratio. Por mais que nosso tempo insista em querer eliminar a verdade objetiva, no fundo sabemos que há certo e "errados" objetivos e que a decisão do agir é um problema de ratio, de recta ratio... Quando, diante de uma ação, perguntamos: "por quê?", estamos perguntando é pela razão (reason, raison...): "Por que razão você fez isto?". E o mesmo ocorre quando, diante de uma ação, dizemos: "É, você tem razão..."; "está coberto de razão"; etc. E, para uma ação que é um grave mal moral, dizemos: "Que absurdo!" (falta razão). 
Isto não quer dizer que a pessoa tenha sempre uma justificativa racional pronta, consciente para cada ato. A prudência decide bem, mas com a espontaneidade da virtude. Aliás, segundo Tomás, a função da virtude (como a de todo hábito, em geral) é precisamente a de permitir realizar o ato com facilidade, "espontaneamente", com certo "automatismo" que não tira a liberdade, antes, pelo contrário (quem objetaria a espontaneidade adquirida - após árduos esforços - dos hábitos para extrair acordes do piano, falar uma língua estrangeira ou andar de bicicleta?).

Mas esse hábito, insistamos, não se dá sobre critérios “certinhos". Tomás observa que, em suas decisões concretas, não pode o homem reger-se por verdades necessárias, mas somente pelo que acontece in pluribus (geralmente).

Note-se que esta é também a razão da insegurança em tantas decisões humanas: a prudentia traz consigo aquele enfrentamento do peso da incerteza, que tende a paralisar os imprudentes.

É dessa dramática imprudência da indecisão que falam alguns clássicos da literatura: do "to be or not to be..." de Hamlet aos dilemas kafkianos (o remorso impõe-se a qualquer decisão), passando pelo "Grande Inquisidor", de Dostoiévski, que descreve "o homem esmagado sob essa carga terrível: a liberdade de escolher" (DOSTOIÉVSKI, s.d.: p.226) e apresenta a massa que abdicou da prudência e se deixa escravizar, preferindo "até mesmo a morte à liberdade de discernir entre o bem e o mal" (p. 225). E, assim, os subjugados declaram de bom grado: "Reduzi-nos à servidão, contanto que nos alimenteis" (p. 224).

Erradamente, nós pretendemos não necessitar de uma virtude (toda a profunda antropologia das virtudes cardeais deixou de existir para nós), pois presumimos dispor de recursos técnicos ou científicos que permitam tornar dispensável o âmbito moral, a virtude cardeal da prudência. Mas, não por acaso, "cardeal" vem da palavra latina cardus, gonzo, eixo em torno do qual se abre a porta (a porta da realização humana, do to be). Abdicar da Prudentia, a cardeal das cardeais, significa perder o eixo, o gonzo, tornar-se des-engonçado existencialmente! Abdicar da prudência é abdicar da realidade e confiarmos a um Ersatz - como ao Grande Inquisidor - as decisões fundamentais da existência...

\section{Os pecados capitais - o vício capital da acídia}

A BBC anunciou, em março de 2008, o que os jornalistas chamam de "barriga", notícia mal apurada que depois não se confirma. A Igreja Católica, disse a BBC, elaborara nova lista de pecados capitais, o que foi desmentido pelo Vaticano. 
A confusão originou-se em entrevista de Gianfranco Girotti, bispo regente da Penitenciaria Apostólica, órgão para matérias do foro interno, como absolvição de pecados especiais, reservados à Santa Sé. Ele respondeu a uma pergunta sobre novos pecados e a mídia extrapolou para novos "sete pecados capitais".

O caso mostrou que a sesquimilenar ideia de pensar as forças da autodestruição em pecados capitais exerce ainda forte atração no homem contemporâneo. Ideia genial: a organização de dezenas de vícios em poucos eixos, que, consolidados em sete, têm o atrativo adicional que tal número produz na imaginação.

Comparada à doutrina dos mandamentos, a dos pecados capitais não tem, na história, fixidez em número e conteúdo: na origem, eram oito e, de autor a autor, variam num ou noutro elemento semântico.

O atual Catecismo da Igreja Católica, no ponto 1.866, traz como pecados capitais: soberba, avareza, inveja, ira, impureza, gula e preguiça ou acídia.

Sugestiva, intrigante, ambiguidade: a familiar preguiça ou a desconhecida acídia? Ou o Catecismo as vê como sinônimas? Na verdade, parece não se querer propor como capital um pecado do qual ninguém ouviu falar; e talvez se tenha vergonha de alçar, sem mais, a inofensiva preguiça ao posto.

Se a preguiça parece pecadilho, a acídia é coisa séria: é a tristeza pelo bem espiritual; a queimadura interior de quem recusa os bens do espírito.

Por séculos, essa tristeza foi pecado capital. O filósofo alemão Josef Pieper (1976, 393-394) nota que não há conceito ético mais aburguesado na consciência cristã, que o de acídia e faz uma formulação forte:

O fato de que a preguiça esteja entre os pecados capitais parece que é, por assim dizer, uma confirmação e sanção religiosa da ordem capitalista de trabalho. Ora, esta ideia é não só uma banalização e esvaziamento do conceito primário teológico-moral da acídia, mas até mesmo sua verdadeira inversão.

Para São Gregório Magno (morto em 604), os pecados capitais são: vanglória, inveja, ira, tristeza, avareza, gula e luxúria. Se os mandamentos estão na Bíblia, os vícios capitais são elaboração de pensamento, fruto da "experiência cristã", a dos padres do deserto, que realizaram uma tomografia da alma e descobriram possibilidades para o bem e o mal.

Como num rali, em que as máquinas passam por condições extremas, o monaquismo originário testava os limites antropológicos, no corpo e no espírito (jejum, vigília, oração, etc.). Nesse quadro, surgiu a doutrina dos pecados capitais.

As primeiras tentativas de organizar essa experiência remontam a Evágrio Pôntico, João Cassiano e Gregório Magno, mas só muito depois há a 
consolidação de Tomás de Aquino, que repensa (de modo amplo e sistemático) a antropologia subjacente aos vícios capitais.

Os vícios capitais, para Tomás, são: vaidade, avareza, inveja, ira, luxúria, gula e acídia.

Derivam de caput: cabeça, líder, chefe; sete poderosos chefões que comandam, produzem outros vícios subordinados. Assim, são vícios que gozam de especial "liderança" (nos dois sentidos: estão em primeiro lugar e dirigem, são leaders).

Vício é restrição à autêntica liberdade e condicionamento para agir mal. A acídia é tristeza: a tristeza pelo bem espiritual, do homem que abdica da estatura existencial a que está chamado. Não só é um mal, mas fonte de outros males.

Como já dissemos, vício capital é aquele do qual naturalmente procedem - a título de finalidade - outros vícios. E, assim como os homens fazem muitas coisas por causa do prazer - para obtê-lo ou movidos pelo impulso do prazer - assim também fazem muitas coisas por causa da tristeza: para evitá-la ou arrastados pelo peso da tristeza. E esse tipo de tristeza, a acídia, é convenientemente situado como vício capital (Summa Theol. II-II q. 35, a.4).

Acídia é base de atitudes contrárias: uma leva à ação, a um desenfreado ativismo; outra é inação (o momento, secundário, em que acídia e preguiça se ligam). Se a tristeza da acídia leva à inação, leva também à inquietude, à ação frenética.

Para já, vale o poema A troca de pneu (Der Radwechsel) de Bertolt Brecht:

Fico sentado à beira da estrada

O chofer troca o pneu

Não "tô legal", lá de onde venho

Não "tô legal", lá para onde vou

Por que sigo a troca do pneu

Com impaciência?

No fazer e no não-fazer, o tédio. Fernando Pessoa, no Livro do desassossego (1982, \#263), diagnostica tal tédio em múltiplos aspectos; limitemo-nos à passagem em que o problema não está no trabalho ou no repouso, mas no centro do eu:

O tédio... Trabalho bastante. Cumpro o que os moralistas da acção chamariam o meu dever social. Cumpro esse dever, ou essa sorte, sem grande esforço nem notável desinteligência. Mas, umas vezes em pleno trabalho, outras vezes no pleno descanso que, segundo os mesmos moralistas, mereço e me deve ser grato, transborda-se-me a alma de um fel de inércia, e estou cansado, não da obra ou do repouso, mas de mim. 
Como vício capital, a acídia tem filhas e, neste ponto, a análise de Tomás adquire espantosa atualidade.

A primeira é o desespero, a que Pieper liga uma "irmã", a pusilanimidade. Paralisado pela vertigem, pelo medo das alturas espirituais e existenciais a que o homem está chamado, não há ânimo ou vontade de ser tão grande como está convocado a ser; abdica-se do "torna-te o que és", a sentença com que Píndaro resume toda ética. Se passamos ao plano da graça, a acídia é um aborrecer-se de que Deus o tenha elevado ao plano da filiação divina, à participação em sua vida.

Queimado por essa tristeza suicida, surge a evagatio mentis, a dispersão de quem renuncia a seu centro interior e entrega-se à importunitas: abandonar a torre do espírito para derramar-se no variado, afogando a sede na água salgada de compensações e prazeres da ação desenfreada: o falatório inócuo (verbositas); o agitar-se (instabilitas); a incapacidade de concentrar-se num propósito (instabilitas); e um afã desordenado de sensações e conhecimento (curiositas).

Evidentes os perigos: desenraizamento, abdicação do processo de autorrealização do eu, que passa a espalhar-se no variado (ad diversa se diffundere). Se já Pascal, em Pensamentos (136/139), diz que a infelicidade vem de o homem não poder estar a sós num quarto, hoje as possibilidades de dispersão se ampliaram.

\section{Considerações Finais}

Ao concluir este esboço de alguns tópicos da ética de Tomás, destaquemos quatro pontos, um para cada item, talvez oportunos para o diálogo com o educador de hoje.

A própria concepção de ética como autorrealização (x autodestruição) sugere-nos outra perspectiva da educação moral: focada não na reivindicação de meus direitos em justiça (sem dúvida, legítima), mas na autodestruição que produz em mim a violação do direito do outro (to be or not to be...).

Em que medida nossa educação considera o homem como uma unidade alma-corpo, espírito-matéria? Continuamos operando numa clave dualista cartesiana: a educação é intelectual; e o corpo fica relegado à "educação física"?

Qualquer atentado contra a prudentia tem como pressuposto a despersonalização, a falta de confiança na pessoa, considerada sempre "menor de idade" e incapaz de decidir e, portanto, devendo transferir a direção de sua vida para outra instância: a igreja, o estado etc. Em qualquer caso, isso é sempre muito perigoso. Como é perigoso que a educação não se lembre dessa virtude...

A atualidade da acídia. A tristeza da acídia é força destruidora, convidando a (ou impondo) compulsões: das drogas ao jogo; do consumismo ao 
workaholism etc. Por trás disso, não há algo daquela desperatio, da curiositas, da evagatio mentis (pense-se, por exemplo, na compulsão por videogames, tablets e celulares; comunicação constante em redes sociais etc.), da instabilitas?

\section{Referências bibliográficas}

DOSTOIÉVSKI, F. Os irmãos Karamázovi. São Paulo: Ouro, s.d.

GUIMARÃES ROSA, João Grande Sertão: Veredas. 5. ed. Rio de Janeiro: José Olympio, 1967.

PIEPER, J. Virtudes fundamentales. Madrid: Rialp, 1976.

PESSOA, Fernando. Livro do desassossego por Bernardo Soares. Lisboa: Edições Ática, 1982.

TOMÁS DE AQUINO. Obras completas. In: Roberto Busa (Ed.). Thomae Aquinatis Opera Omnia cum hypertextibus in CD-ROM. Milano: Editoria Elettronica Editel, 1992.

TOMÁS DE AQUINO. A Prudência: a virtude da decisão certa. Tradução, estudos introdutórios e notas de Jean Lauand. São Paulo: WMF Martins Fontes, 2014.

TOMÁS DE AQUINO. Sobre o ensino e os sete pecados capitais. Tradução, estudos introdutórios e notas de Jean Lauand. São Paulo: Martins Fontes, selo Martins 2004.

Submetido em: 10-5-2017

Aceito em: 5-6-2017 